\title{
Neto Auxiliary Protein Interactions Regulate Kainate and NMDA Receptor Subunit Localization at Mossy Fiber-CA3 Pyramidal Cell Synapses
}

\author{
Megan S. Wyeth, ${ }^{1}$ Kenneth A. Pelkey, ${ }^{1}$ Ronald S. Petralia, ${ }^{2}$ Michael W. Salter, ${ }^{3}$ Roderick R. McInnes, ${ }^{4}$ \\ and Chris J. McBain ${ }^{1}$ \\ ${ }^{1}$ Eunice Kennedy Shriver National Institute of Child Health and Human Development, National Institutes of Health, MSC 3715, Bethesda, Maryland 20892, \\ ${ }^{2}$ National Institute on Deafness and Other Communication Disorders, National Institutes of Health, MSC 8027, Bethesda, Maryland 20892, ${ }^{3}$ Program in \\ Neurosciences and Mental Health, Hospital for Sick Children, and Department of Physiology, University of Toronto, Toronto, Ontario M5G 1X8, Canada, \\ and ${ }^{4}$ Lady Davis Research Institute, Jewish General Hospital and Departments of Human Genetics and Biochemistry, McGill University, Montréal, Québec \\ H3T 1E2, Canada
}

Neto1 and Neto2 auxiliary subunits coassemble with NMDA receptors (NMDARs) and kainate receptors (KARs) to modulate their function. In the hippocampus, Netol enhances the amplitude and prolongs the kinetics of KAR-mediated currents at mossy fiber (MF)-CA3 pyramidal cell synapses. However, whether Netol trafficks KARs to synapses or simply alters channel properties is unresolved. Therefore, postembedding electron microscopy was performed to investigate the localization of GluK2/3 subunits at MF-CA3 synapses in Neto-null mice. Postsynaptic GluK2/3 Immunogold labeling was substantially reduced in Neto-null mice compared with wild types. Moreover, spontaneous KAR-mediated synaptic currents and metabotropic KAR signaling were absent in CA3 pyramidal cells of Neto-null mice. A similar loss of ionotropic and metabotropic KAR function was observed in Neto1, but not Neto2, single knock-out mice, specifically implicating Netol in regulating CA3 pyramidal cell KAR localization and function. Additional controversy pertains to the role of Neto proteins in modulating synaptic NMDARs. While Immunogold labeling for GluN2A at MF-CA3 synapses was comparable between wild-type and Neto-null mice, labeling for postsynaptic GluN2B was robustly increased in Neto-null mice. Accordingly, NMDARmediated currents at MF-CA3 synapses exhibited increased sensitivity to a GluN2B-selective antagonist in Neto1 knockouts relative to wild types. Thus, despite preservation of the overall MF-CA3 synaptic NMDAR-mediated current, loss of Neto1 alters NMDAR subunit composition. These results confirm that Neto protein interactions regulate synaptic localization of KAR and NMDAR subunits at MFCA3 synapses, with implications for both ionotropic and metabotropic glutamatergic recruitment of the CA3 network.

Key words: electron microscopy; kainate receptor; metabotropic; mossy fiber pathway; Neto1 or Neto2; NMDAR

\section{Introduction}

Auxiliary proteins coassemble with receptors/channels to modify their inherent biophysical features, altering function and, in some cases, regulating subcellular targeting (Yan and Tomita, 2012). The discovery of transmembrane proteins Netol and Neto2 as auxiliary kainate receptor (KAR) subunits elucidated

Received July 18, 2013; revised Nov. 22, 2013; accepted Nov. 22, 2013.

Author contributions: M.S.W., K.A.P., R.S.P., and C.J.M. designed research; M.S.W., K.A.P., and R.S.P. performed research; M.S.W. and K.A.P. analyzed data; M.S.W., K.A.P., R.S.P., M.W.S., R.R.M., and C.J.M. wrote the paper.

C.J.M. was supported by the National Institute of Child Health and Human Development Intramural Research Program; R.S.P. was supported by the National Institute on Deafness and 0ther Communication Disorders Intramural Research Program; M.S.W. was supported by an NIGMS Intramural Postdoctoral Research Associate Fellowship; M.W.S. was supported by a Canada Research Chair, and the Anne and Max Tanenbaum Chair in Molecular Medicine; and R.R.M. was supported by Canadian Institutes of Health Research Grants MOP-7315 and IOP-54037, and a Canada Research Chair. We thank Ya-Xian Wang for help with electron microscopy.

The authors declare no competing financial interests.

Correspondence should be addressed to Chris J. McBain, Program in Developmental Neurobiology, Section on Cellular and Synaptic Neurophysiology, NICHD, National Institutes of Health, Porter Neuroscience Building, Room 3C903, 35 Lincoln Drive, MSC 3715, Bethesda, MD 20892. E-mail: mcbainc@mail.nih.gov.

DOI:10.1523/JNEUROSCI.3098-13.2014

Copyright $\odot 2014$ the authors $\quad 0270-6474 / 14 / 340622-07 \$ 15.00 / 0$ why currents mediated by heterologously expressed KARs are small and brief relative to native KARs (Zhang et al., 2009; Tomita and Castillo, 2012; for review see Copits and Swanson, 2012). In general, Neto1 and Neto2 directly interact with KAR subunits to increase channel function by modulating gating properties (Zhang et al., 2009; Copits et al., 2011; Fisher and Mott, 2013). Neto1 knock-out mice exhibit dramatic deficits in postsynaptic KAR function at hippocampal mossy fiber (MF)-CA3 pyramidal cell synapses where Neto 1 is abundant and KARs critically regulate synaptic function (Straub et al., 2011; Tang et al., 2011). An additional role for Netol in targeting KARs to synapses is controversial, with contradictory results obtained in different cell types and with different experimental approaches (Copits et al., 2011; Straub et al., 2011; Tang et al., 2011).

Further controversy surrounds the role of Neto1 in regulating NMDA receptor (NMDAR) function. At Schaffer collateral (SC)-CA1 pyramidal cell synapses in Neto1 knock-out mice, an impaired long-term potentiation phenotype with associated learning and memory deficits, was linked to reduced NMDAR currents attributed to decreased postsynaptic GluN2A 
(Ng et al., 2009). A similar reduction in NMDAR-mediated transmission at associational/commissural inputs to CA3 pyramidal cells of Neto1 knockouts was reported in one study (Tang et al., 2011) but not in another (Straub et al., 2011). Moreover, neither study observed a deficit in NMDAR transmission at MF-CA3 synapses of Neto1 knockouts (Straub et al., 2011; Tang et al., 2011).

This study took advantage of the resolution afforded by Immunogold electron microscopy to clarify whether Neto interactions are important for postsynaptic targeting of KAR and NMDAR subunits at MF-CA3 synapses. The ultrastructural investigation was complemented with further electrophysiological interrogation of CA3 pyramidal cells to evaluate whether Neto interactions also regulate metabotropic KAR signaling, and to probe for more subtle alterations to NMDAR transmission at MF-CA3 synapses.

\section{Materials and Methods}

Animals. Receptor subunit expression was investigated with electron microscopy on male (6 weeks old) wild-type and Neto1/Neto2 knockout (Neto-null) mice ( 3 each). The GluK2/3 antibody was tested in two GluK1/2 knock-out mice. Electrophysiology was conducted on P14-P35 wild-type, Neto1 knock-out, Neto2 knock-out, and Netonull mice (same lines used in Ng et al., 2009 and Tang et al., 2011). All procedures relating to animal care and treatment conformed to NIH guidelines.

Antisera. To investigate changes in receptor subunit expression, rabbit anti-GluK2/3 (catalog \#04-921, Millipore) was used at 1:50 (Fernandes et al., 2009). Rabbit anti-GluN2A (catalog \#GluRe1C-Rb-Af543, Frontier Science) was used at 1:50, and rabbit anti-GluN2B (catalog \#GluRe2CRb-Af300, Frontier Science) was used at 1:25 (Petralia et al., 2005).

Postembedding electron microscopy. Mice were anesthetized and perfused through the ascending aorta with fresh $4 \%$ PFA and $0.5 \%$ glutaraldehyde in $0.12 \mathrm{~m}$ phosphate buffer at room temperature. Horizontal sections were processed with freeze substitution and low-temperature embedding. Ultrathin sections were labeled using secondary antibody conjugated to $5 \mathrm{~nm}$ colloidal gold particles (1:40) and examined on a JEOL JEM-1010. All procedures followed previously detailed methods (Petralia and Wenthold, 1999).

Immunolabeling quantitation. MF-CA3 synapses were randomly sampled (unsystematically) throughout CA3 stratum lucidum. Analysis was blinded for the experiments testing antibody specificity. The length of the postsynaptic density (PSD) for every distinct synapse (labeled or not) was measured in ImageJ to calculate the density of postsynaptic gold particles. Particles were counted as postsynaptic if they were in the PSD, within $20 \mathrm{~nm}$ from the synaptic membrane to allow for distance added by the antibodies. Gold particles in the cleft were considered postsynaptic if they were closest to that membrane. For each subunit, 240-578 synapses per genotype (at least 50 per mouse) were analyzed, with significance determined by independent-samples Kruskal-Wallis test.

Electrophysiology. Whole-cell recordings in voltage-clamp mode were made from CA3 pyramidal neurons in transverse vibratome slices (300 $\mu \mathrm{m})$ cut in ice-cold saline solution ( $130 \mathrm{~mm} \mathrm{NaCl}, 24 \mathrm{~mm} \mathrm{NaHCO} 3,3.5$ $\mathrm{mm} \mathrm{KCl}, 1.25 \mathrm{~mm} \mathrm{NaH}_{2} \mathrm{PO}_{4}, 0.5 \mathrm{~mm} \mathrm{CaCl}_{2}, 4.5 \mathrm{~mm} \mathrm{MgCl}_{2}$, and $10 \mathrm{~mm}$ glucose, saturated with $95 \% \mathrm{O}_{2}$ and $5 \% \mathrm{CO}_{2}, \mathrm{pH} 7.4$ ) and incubated for a minimum of $30 \mathrm{~min}$ at $35^{\circ} \mathrm{C}$. In the recording chamber, slices were perfused $(2-3 \mathrm{ml} / \mathrm{min}$ ) with extracellular solution ( $130 \mathrm{~mm} \mathrm{NaCl}, 24 \mathrm{~mm}$ $\mathrm{NaHCO}_{3}, 3.5 \mathrm{~mm} \mathrm{KCl}, 1.25 \mathrm{~mm} \mathrm{NaH}_{2} \mathrm{PO}_{4}, 2.5 \mathrm{~mm} \mathrm{CaCl}_{2}, 1.5 \mathrm{~mm} \mathrm{MgCl}_{2}$, $10 \mathrm{~mm}$ glucose, and $0.005-0.010 \mathrm{~mm}$ bicuculline methiodide saturated with $95 \% \mathrm{O}_{2}$ and $5 \% \mathrm{CO}_{2}$, pH $7.4,32-35^{\circ} \mathrm{C}$ ).

To examine spontaneous EPSCs (sEPSCs) and metabotropic KAR function, recording electrodes $(4-5 \mathrm{M} \Omega$ ) were filled with a potassium methylsulfate-based intracellular solution to stabilize the slow afterhyperpolarization current ( $I_{\mathrm{sAHP}}$; Fisahn et al., 2005), as follows: $150 \mathrm{~mm}$ $\mathrm{KCH}_{3} \mathrm{SO}_{4}, 10 \mathrm{~mm} \mathrm{KCl}, 10 \mathrm{~mm}$ HEPES, $4 \mathrm{~mm} \mathrm{NaCl}, 4 \mathrm{~mm} \mathrm{Mg} \mathrm{M}_{2} \mathrm{ATP}$, and $0.4 \mathrm{mM} \mathrm{Na}_{4} \mathrm{GTP}, 290-300 \mathrm{mOsm}, \mathrm{pH}$ 7.3. $I_{\mathrm{sAHP}}$ was evoked at $1 \mathrm{~min}$ intervals with a depolarizing pulse $(50 \mathrm{mV} / 150 \mathrm{~ms})$ from a holding po-
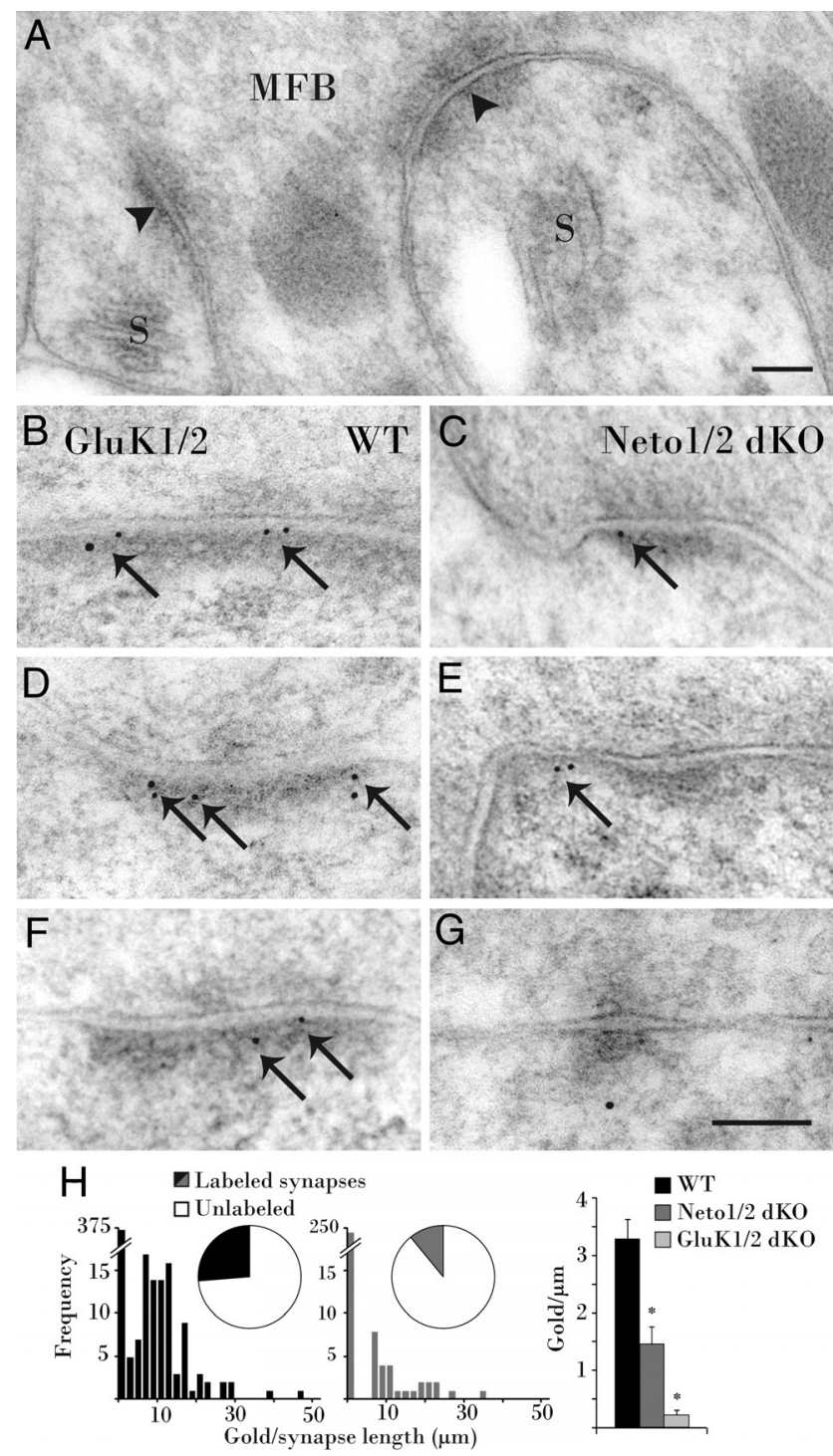

Figure 1. GluK2/3 immunolabeling is reduced at MF-CA3 PSDs in Net01/2 double K0 (dKO) mice. $A, A$ large MFB characteristically encompasses and forms asymmetric synapses (arrowheads) with two thorny excrescent spines, each containing a spine apparatus (S). $\boldsymbol{B}, \boldsymbol{D}, \boldsymbol{F}$, In wild-type (WT) mice, GluK2/3 subunits are prevalent (arrows) at the PSD of CA3 complex spines synapsing with MFBs. $\boldsymbol{C}$, In a Neto-null mouse, Immunogold also labels GluK2/3 at an asymmetric synapse in stratum lucidum (arrow). $\boldsymbol{E}, \mathbf{G}$, Extrasynaptic (arrow) and cytoplasmic colloidal gold leave synapses unlabeled in a Neto-null mouse. $\boldsymbol{H}$, Pie charts demonstrate that fewer synapses are labeled in Neto-null than WT mice, and histograms display the combined density distribution of PSD gold particles. The average density of gold particles in Neto-null mice is less than half the density at WT synapses (far right), while minimal labeling in GluK1/2 knockouts demonstrates GluK2/3 antibody specificity. Scale bar, $100 \mathrm{~nm}$.

tential $\left(V_{\mathrm{h}}\right)$ of $-50 \mathrm{mV} . I_{\text {sAHP }}$ amplitude (determined $450 \mathrm{~ms}$ after the depolarizing pulse) was allowed to stabilize for 10-25 min before kainate (200 nM) application in the presence of [1-(4-aminophenyl)-4-methyl7,8-methylenedioxy-5H-2,3-benzodiazepine] (GYKI)-53655 (0.05 mm). sEPSCs were detected by template matching and a minimum 100 events/ cell were averaged to determine the weighted decay time constant from a double exponential fit.

Evoked NMDAR-mediated transmission at MF-CA3 synapses was examined using an intracellular solution composed of the following: 95 mM Cs-gluconate, $5 \mathrm{~mm} \mathrm{CsCl,} 0.6 \mathrm{~mm}$ EGTA, $5 \mathrm{~mm} \mathrm{MgCl}_{2}, 4 \mathrm{~mm} \mathrm{NaCl}, 2$ mm Na 2 ATP, 0.3 mm NaGTP, 40 mm HEPES, 10 mm BAPTA, and $1 \mathrm{~mm}$ QX-314, pH 7.2-7.3, 290-300 mOsm. Synaptic responses (paired pulses, $20 \mathrm{~Hz}$ ) were evoked at $0.1-0.2 \mathrm{~Hz}$ by low-intensity microstimulation in 

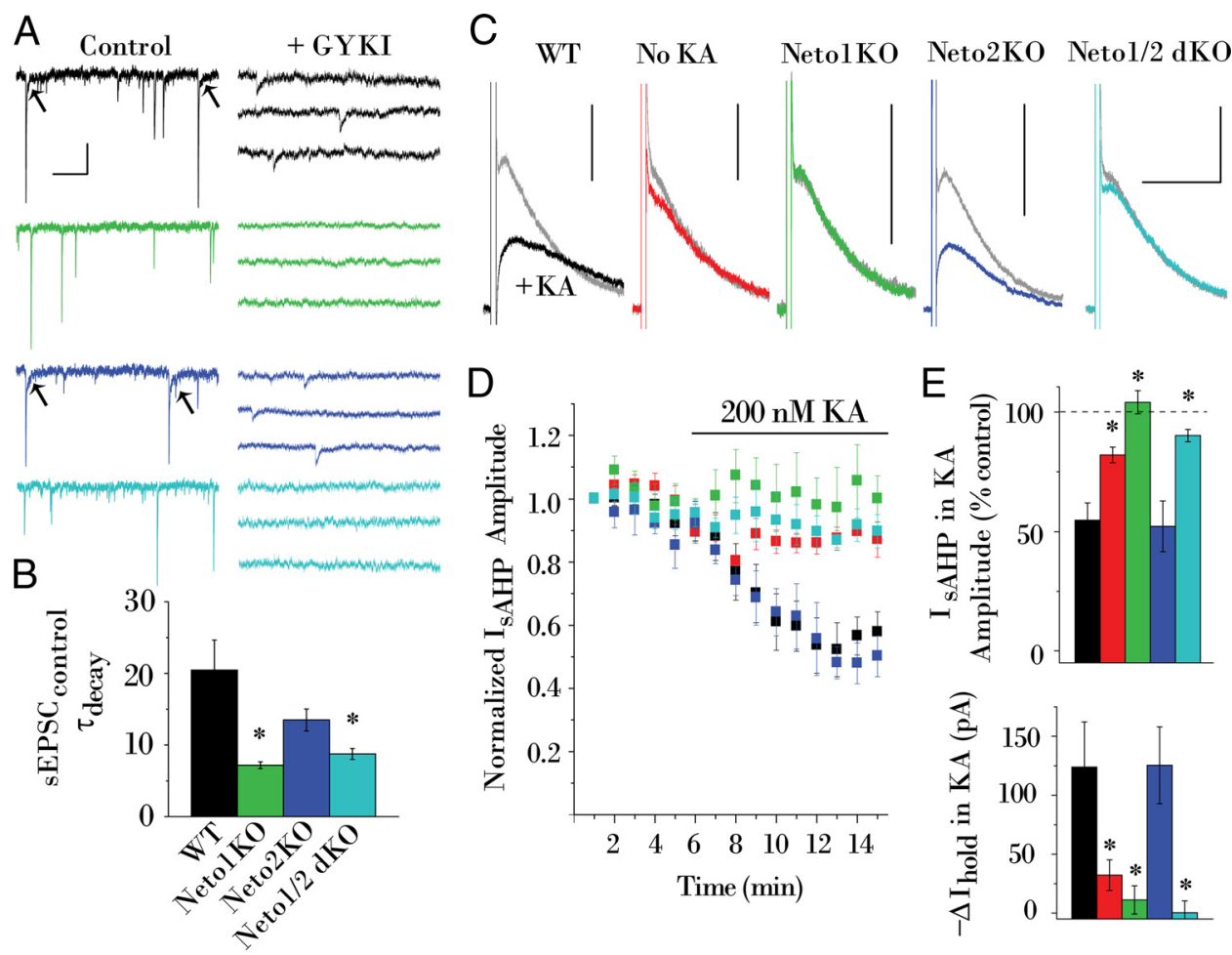

Figure 2. Ionotropic and metabotropic KAR functions are deficient in the absence of Net01. A, AMPAR-mediated currents dominate sEPSCS (Control) before GYKI-53655 isolates $\mathrm{SEPSC}_{\mathrm{KA}} \mathrm{S}$ in a wild-type (black) and Net02KO (blue) cell; but sEPSC $\mathrm{KA}_{\mathrm{A}}$ s are undetectable in a Neto1KO (green) or Neto-null (cyan) cell following GYKI-53655. $\boldsymbol{B}$, The average $\tau_{\text {decay }}$ of sEPSCs (before GYKI-53655) is faster in Net01KO $(n=8)$ and Neto-null $(n=15)$ cells, consistent with a loss of the slow KAR contribution to a subset of the sEPSCs that was present in WT ( $n=$ 8 ) and Neto2KO $(n=7)$ cells $(\boldsymbol{A}$, arrows). Note that MF-CA3 synapse sEPSCs represent only a fraction of the entire sEPSC population collected, thus only a subset of the events contain a KAR-mediated component. C, KA reduces $I_{\text {SAHP }}$ (gray) in a WT and Neto2KO cell, but fails to reduce $I_{\text {SAHP }}$ in a Neto1KO or Neto-null cell. A control WT cell not exposed to KA is shown for comparison (red). D. Time course plot summarizing the effects of KA application upon $I_{\text {sAHP }}$ in WT $(n=8)$, Neto $1 K 0(n=6)$, Neto2KO $(n=5)$, and Neto-null $(n=10)$ cells, and untreated controls $(n=8)$. $I_{\text {SAHP }}$ amplitude was normalized to the value measured 3 min before beginning KA application. $E$, Histogram summarizing the effects of KA or vehicle upon $I_{\text {sAHP }}$ after 10 min perfusion. Also plotted are average changes in $V_{h}$ observed upon KA (or vehicle) application. Calibration: $A, 5 \mathrm{~s}, 50 \mathrm{pA} ; \mathrm{C}, 5 \mathrm{~s}, 100 \mathrm{pA} .{ }^{*} p<0.05$ versus WT control datasets (black bars in $\boldsymbol{B}$ and $\boldsymbol{E}$ ). dKO, Double KO.

stratum lucidum. The MF origin of EPSCs was first confirmed by a rapidly rising, strongly facilitating AMPA receptor-mediated component at $V_{\mathrm{h}}$ of $-70 \mathrm{mV}$, following which the pharmacologically isolated NMDAR-mediated component (DNQX, $0.010 \mathrm{~mm} ; V_{\mathrm{h}}=+40 \mathrm{mV}$ ) was probed with ifenprodil $(0.005 \mathrm{~mm})$. Statistical significance was assessed using parametric (unpaired $t$ tests) or nonparametric (Mann-Whitney $U$ test) tests, as appropriate.

\section{Results}

Reduced postsynaptic GluK2/3 on CA3 pyramidal cell spines in Neto-null mice

Prior studies provided conflicting evidence as to whether Neto 1 participates in localizing postsynaptic KARs to MFCA3 synapses (Straub et al., 2011; Tang et al., 2011). Postembedding immunoelectron microscopy was therefore conducted to examine GluK2/3 expression at the ultrastructural level. MF boutons (MFBs) are clearly identifiable by their large size and often engulf protruding thorny excrescent spines of CA3 pyramidal cells (Fig. $1 A$ ). In wild-type mice, Immunogold particles abundantly labeled GluK2/3 at PSDs of CA3 complex spines contacting MFBs (Fig. $1 B, D, F$ ). In Netonull mice, GluK2/3 was found at the PSD of some complex spines (Fig. 1C); however, labeling was notably decreased, with many synapses unlabeled (Fig. $1 E, G$ ). Fewer MF-CA3 synapses were labeled in Neto-null mice (11\%) than in the wild types (26\%), reducing the density of postsynaptic Immunogold by half $(3.3 \pm 0.3$ gold particles/ $\mu \mathrm{m}$ in wild-type mice vs $1.5 \pm 0.3$ gold particles $/ \mu \mathrm{m}$ in Neto-null mice; Kruskal-
Wallis test, $p=0.0000047$; Fig. $1 H)$. By comparison, GluK2/3 labeling was essentially absent in GluK1/2 knock-out mice $(0.2 \pm 0.000018$ gold particles $/ \mu \mathrm{m} ; p=-0.00000000043$; Fig. $1 H)$, reflecting the specificity of the antibody. These data are consistent with Neto interactions influencing GluK2/3 postsynaptic targeting.

\section{Reduced ionotropic and metabotropic KAR signaling in Neto1 knock-out mice}

Despite conflicting observations concerning the role of Netol in KAR synaptic localization, studies agree on dramatic deficits in MF-evoked KAR-mediated currents in Neto1 knock-out mice (Straub et al., 2011; Tang et al., 2011). In accord with these findings, this study found that loss of Neto1, but not Neto2, eliminated a slowly decaying component of mixed AMPA/KA sEPSCs that was consistently present in a subpopulation of events recorded in wild-type CA3 pyramidal cells (Fig. 2A,B). Moreover, while wild-type (and Neto2 knock-out) mice typically exhibited kinetically slow sEPSCs resistant to the AMPAR antagonist GYKI-53655, such unitary KAR-mediated events were absent in Neto1 knock-out (and Neto-null) mice (Fig. 2A). These findings affirm decreased ionotropic KAR function in mice lacking Netol and are consistent with the observed reduction of synaptic KARs in Neto-null mice.

In addition to ionotropic transmission, KARs signal through G-proteins to suppress $I_{\text {sAHP }}$ (Melyan et al., 2002; Fisahn et al., 2005; Ruiz et al., 2005), prompting investigation of a role for Neto 
interactions in regulating metabotropic KAR signaling. The basic properties of $I_{\mathrm{sAHP}}$ were not significantly altered by loss of Netos (maximum $I_{\mathrm{sAHP}}$ amplitudes within the first $10 \mathrm{~min}$ of recording: $235 \pm 28,190 \pm 25,233 \pm 53$, and $299 \pm 44 \mathrm{pA} ; \tau_{\text {decay }}: 1436 \pm 97$, $1521 \pm 99,1430 \pm 62$, and $1426 \pm 55 \mathrm{~ms}$ for wild-type, Neto 1 knock-out, Neto2 knock-out and Neto-null mice, respectively). As previously reported, bath application of kainate $(200 \mathrm{nM}) \mathrm{re}-$ duced $I_{\mathrm{sAHP}}$ in wild-type and Neto2 knock-out mice (Fig. 2C-E). In contrast, kainate failed to depress $I_{\mathrm{sAHP}}$ in Netol knock-out and Neto-null mice (Fig. 2C-E). Furthermore, while $200 \mathrm{~nm}$ kainate consistently produced a strong inward current in wild-type and Neto2 knock-out mice, such kainate-induced currents were absent in mice lacking Neto1 (Fig. 2E), revealing a severe impairment in both synaptic and extrasynaptic KAR function. Considered together, these findings indicate that Netol strongly influences the synaptic localization of CA3 pyramidal cell KAR subunits, and dictates both ionotropic and metabotropic KAR signaling.

\section{Unaltered GluN2A labeling at MF-CA3 synapses in Neto-null mice}

In addition to KARs, Netol reportedly maintains postsynaptic GluN2A at SC-CA1 synapses, resulting in reduced NMDARmediated currents in Neto1 knock-out mice (Ng et al., 2009). Although $\mathrm{EPSC}_{\mathrm{NMDA}} \mathrm{s}$ appeared normal at MF-CA3 synapses in Neto knock-out mice (Straub et al., 2011; Tang et al., 2011), immunoelectron microscopy was undertaken to investigate potential alterations in GluN2A expression. Colloidal gold labeled GluN2A subunits at the PSD of CA3 complex spines in wild-type mice (Fig. $3 A, C, E$ ). In Neto-null mice, GluN2A subunits were similarly observed at the PSD (Fig. $3 B, D, F$ ), with no difference in the percentage of labeled synapses ( $20 \%$ vs $21 \%)$, or the density of labeled GluN2A subunits at PSDs ( $1.4 \pm 0.2$ gold particles $/ \mu \mathrm{m}$ in wild-type mice; $1.6 \pm 0.2$ gold particles $/ \mu \mathrm{m}$ in Neto-null mice; Kruskal-Wallis test, $p=0.8$; Fig. $3 G$ ).

\section{Increased GluN2B at MF-CA3 synapses in Neto-null mice}

Neto1 also associates with GluN2B, which was relatively increased in Neto1 knock-out mice at Schaffer collateral inputs ( Ng et al., 2009), prompting investigation of GluN2B subunit expression at the MF-CA3 synapse. Typically, GluN2B expression declines over development (Petralia et al., 2005), and very low levels are present in stratum lucidum of adult rodents (Fritschy et al., 1998; Watanabe et al., 1998); accordingly, Immunogold only rarely labeled synaptic GluN2B in wild-type mice (Fig. 4A). Occasional gold particles were observed adjacent to synapses (Fig. 4C), while most synapses were unlabeled (Fig. 4E, G). However, in Neto-null mice, MF-CA3 synapses were more frequently and more heavily labeled for GluN2B (Fig. $4 B, D, F$ ), though unlabeled synapses remained (Fig. $4 H$ ). The percentage of labeled synapses was doubled in Neto-null mice relative to wild-type mice (from $6 \%$ to $12 \%$ ), and the distribution revealed that labeled synapses had more particles, compounding to triple the density of postsynaptic Immunogold (from $0.5 \pm 0.1$ gold particles $/ \mu \mathrm{m}$ in wild-type mice to $1.6 \pm$ 0.3 gold particles $/ \mu \mathrm{m}$ in Neto-null mice; Kruskal-Wallis test, $p=0.01$; Fig. $4 I$ ).

\section{Increased ifenprodil sensitivity at MF-CA3 synapses of Neto1} knock-out mice

To corroborate the increased postsynaptic GluN2B labeling observed in Neto-null mice, sensitivity to the GluN2B antagonist ifenprodil was tested at MF-CA3 synapses. Consistent with the

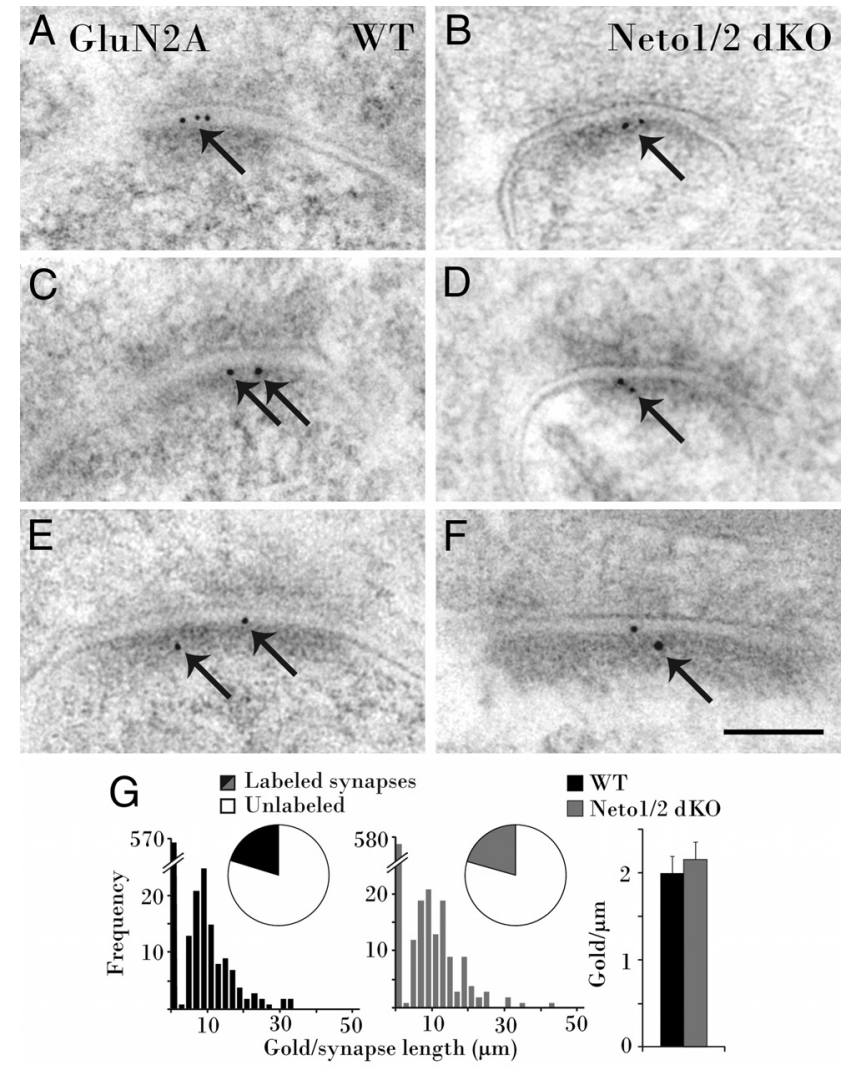

Figure 3. Postembedding labeling for GluN2A is unaltered in the MF pathway of Neto-null mice. $\boldsymbol{A}, \boldsymbol{C}, \boldsymbol{E}$, Multiple Immunogold particles label postsynaptic GluN2A at oblique MF-CA3 synapses in WTs (arrows). $\boldsymbol{B}, \boldsymbol{D}, \boldsymbol{F}$, In Neto-null mice, postsynaptic GluN2A subunits are similarly labeled with Immunogold (arrows). G, The same proportion of synapses is labeled in WT and Neto-null mice, with similar density distributions, resulting in comparable average densities between genotypes. Scale bar, $100 \mathrm{~nm}$. dKO, Double KO.

infrequent expression of synaptic GluN2B, ifenprodil (5 $\mu \mathrm{M})$ only modestly inhibited EPSC $_{\mathrm{NMDA}}$ amplitude in wild-type mice (Fig. $4 J-L$ ). By contrast, in Netol knockouts, ifenprodil yielded significantly greater inhibition (Fig. 4J-L). Although GluN2B subunit-dominated NMDARs are kinetically slower than those dominated by GluN2A subunits (Tovar et al., 2013), no significant difference in EPSC $_{\text {NMDA }}$ decay time constant was found between wild-type mice ( $69 \pm 5.5 \mathrm{~ms}, n=15$ cells) and Neto 1 knockouts ( $77 \pm 9.1 \mathrm{~ms}, n=15$ cells, $p=0.48)$. Nor were any differences observed in the current-voltage relations of MF-CA3 synapse NMDARs (Fig. $4 M$ ). In both genotypes, $\mathrm{EPSC}_{\mathrm{NMDA}} \mathrm{S}$ exhibited strong voltage-dependent block, suggesting minimal contribution of $\mathrm{Mg}^{2+}$-insensitive GluN2C/D NMDARs in wildtype or Neto1 knock-out mice (Berg et al., 2013). Finally, comparison of $\mathrm{EPSC}_{\mathrm{AMPA}} / \mathrm{EPSC}_{\mathrm{NMDA}}$ confirmed that the overall NMDAR current at MF-CA3 synapses was unchanged in Neto1 knock-out mice (Fig. $4 L$ ), which is in agreement with previous reports (Straub et al., 2011; Tang et al., 2011). Together, our electron microscopy and electrophysiological findings indicate that, despite the preservation of synaptic NMDAR-mediated current, the loss of Neto1 alters NMDAR subunit composition at MF-CA3 synapses.

\section{Discussion}

Previous studies obtained conflicting biochemical, electrophysiological, and immunocytochemical evidence as to whether Neto interactions participate in the synaptic localization of 

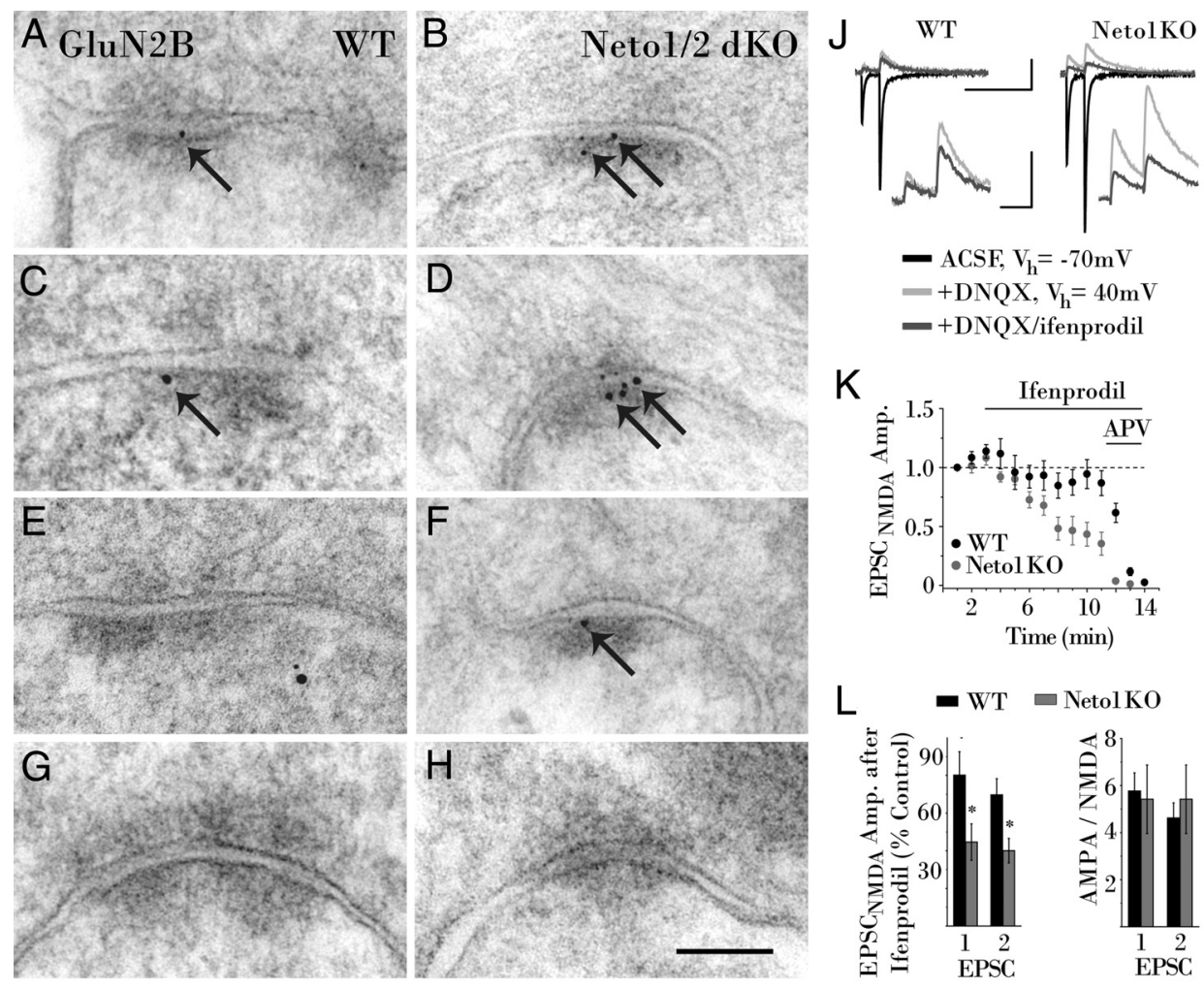

$$
\begin{aligned}
& \text { - ACSF, } \mathrm{V}_{\mathrm{h}}=-70 \mathrm{mV} \\
& +\mathrm{DNQX}, \mathrm{V}_{\mathrm{h}}=40 \mathrm{mV} \\
& -+\mathrm{DNQX} / \text { ifenprodil }
\end{aligned}
$$

$\mathrm{K}$
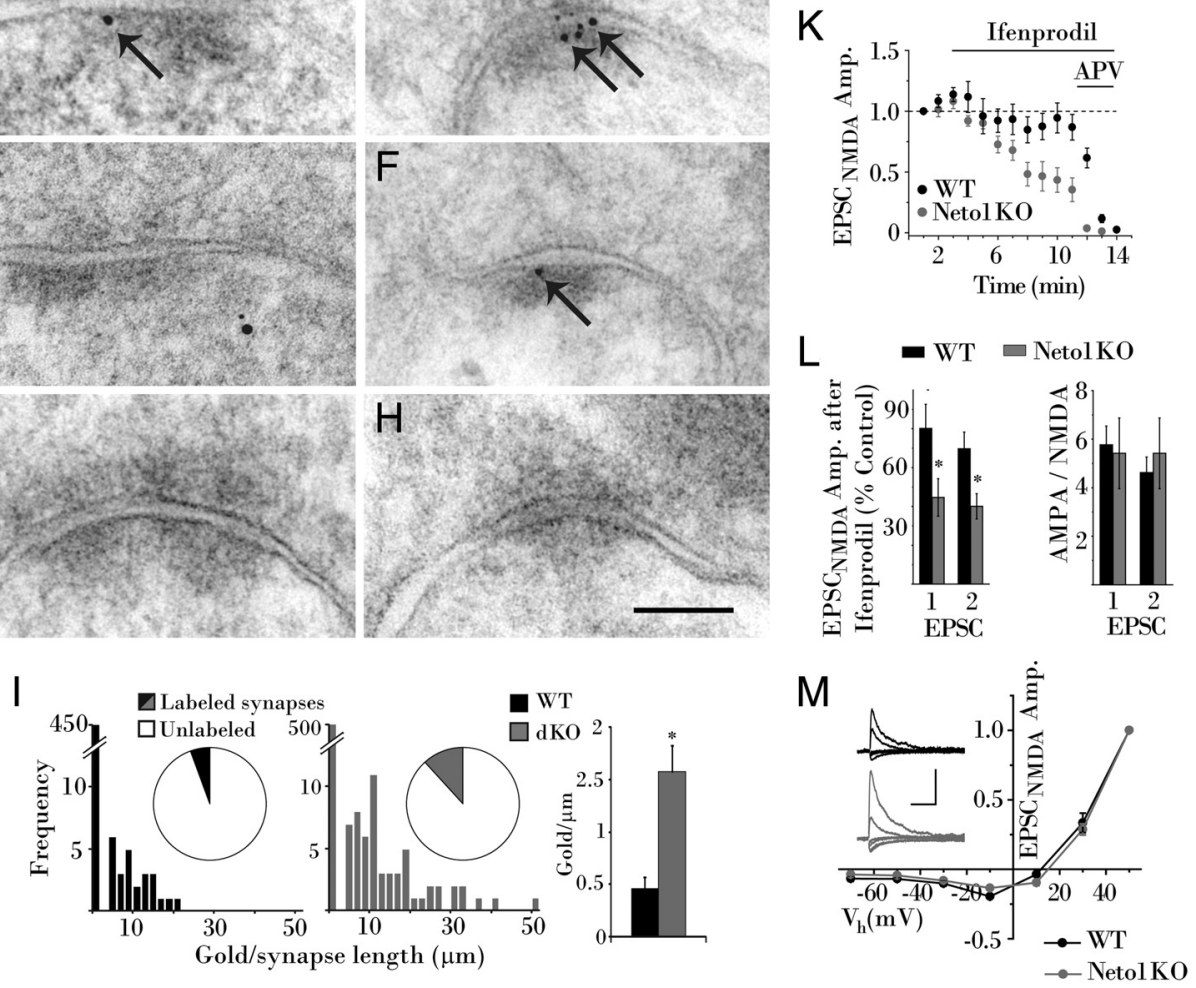

Figure 4. GluN2B expression is increased at MF-CA3 synapses in the absence of Neto interactions. $A, C, E, G$, Colloidal gold (arrow) labels rare postsynaptic GluN2B at an MF-CA3 synapse in a WT mouse, as well as synapse-adjacent ( $\boldsymbol{C}$, arrow) and cytoplasmic GluN2B (E), leaving most synapses unlabeled (G). $\boldsymbol{B}, \boldsymbol{D}, \boldsymbol{F}, \boldsymbol{H}$, In Neto-null mice Immunogold particles (arrows) label postsynaptic GluN2B more robustly $(\boldsymbol{B}, \boldsymbol{D}, \boldsymbol{F})$, while unlabeled synapses are also evident $(\boldsymbol{H})$. $\boldsymbol{I}$, However, a larger portion of synapses are labeled in Neto-null mice, and with greater abundance, combining to increase the average density of postsynaptic gold threefold. J, Greater ifenprodil inhibition of evoked MF-CA3 EPSC ${ }_{\text {NMDA }} s$ (20 consecutive events averaged) in Neto $1 K 0$ than WT mice. $K$, Time course plot (1 min running averages normalized to the first minute) illustrating the effects of ifenprodil on the peak amplitude of EPSC $C_{\text {MMDA }}$ in Neto1KO $(n=6)$ and WT cells $(n=9)$. $L$, Histogram summaries for the effects of ifenprodil on EPSC NMDA $_{\text {, }}$ and AMPA/NMDA ratios, in WT and Neto 1 knock-out mice. Residual EPSC $C_{\text {NMDA }}$ following ifenprodil application is expressed as a percentage of control EPSC $_{\text {NMDA }}$ measured immediately before ifenprodil application. M, MF-CA3 synapse NMDA I-V curves with representative traces (insets) for WT ( $n=7$ ) and Neto 1 knock-out ( $n=7$ ) cells. EPSC $\mathrm{NMDA}_{\text {. }}$ peak amplitudes at each holding potential are normalized to the amplitude obtained at a $V_{\mathrm{h}}=+50 \mathrm{mV}$. Scale bar: $\boldsymbol{A}-\boldsymbol{H}, 100 \mathrm{~nm}$. Calibration:J, $\boldsymbol{K}, 200 \mathrm{~ms}, 200 \mathrm{pA}$; insets, $50 \mathrm{~ms}, 100 \mathrm{pA} ; \boldsymbol{M}, 100 \mathrm{~ms}$, 100 pA. ${ }^{*} p<0.05$. dKO, Double KO.

KAR subunits (Copits et al., 2011; Straub et al., 2011; Tang et al., 2011, 2012). Here, consistent with a role for Neto proteins trafficking KAR to MF-CA3 synapses, electron microscopy revealed a markedly diminished density of postsynaptic GluK2/3 in Neto-null mice relative to wild types, which would contribute to the decreased amplitude of evoked KARmediated currents previously reported at MF-CA3 synapses in mice lacking Neto1 (Straub et al., 2011; Tang et al., 2011). Current and prior electrophysiological findings specifically implicate Netol as the primary mediator of KAR localization in CA3 pyramidal cells.

The observed loss of $\mathrm{sEPSC}_{\mathrm{KA}} \mathrm{s}$ in mice lacking Netol indicated a reduction in receptors beyond that which could be attributed to simple alterations of channel gating. Given that some synaptic GluK2/3 remained in Neto1 knock-out and Neto-null mice, the failure to detect any GYKI-resistant sEPSCs may reflect that the remaining KARs are insensitive to the limited amount of available glutamate provided by unitary release events, as Neto 1 interactions greatly enhance KAR affinity for glutamate. Alternatively, unitary $\mathrm{EPSC}_{\mathrm{KA}}$ s may simply fall below the limits of detection, as even with multiple fiber train stimulation to facilitate glutamate release, KAR-mediated events were reduced by half (relative to AMPAR-mediated events) in cells lacking Netol (Tang et al., 2011). The further inability for $200 \mathrm{~nm}$ bath-applied kainate to produce any significant inward current in the absence of Neto 1 (compare with Fig. 2D) likely reflects combined deficits in KAR gating and overall membrane targeting in CA3 pyramidal cells. Such a general KAR membrane targeting a role for Neto proteins is likely to be highly cell type-, receptor subunit-, and Neto isoform-dependent, as conflicting findings have emerged for various recombinant expression systems with different KAR subunits in combination with Neto1 or Neto2 (Zhang et al., 2009; Copits et al., 2011). 
Compromised metabotropic KAR alleviation of the $I_{\mathrm{sAHP}}$ at the MF-CA3 synapse in cells without Neto1 may indicate that Neto1 confers metabotropic KAR function (for instance, by serving as an intermediary for G-protein interactions), or may simply reflect insufficient KAR activation due to scarce KAR surface expression or lower kainate affinity of Neto-less KARs. A higher kainate concentration may be required to trigger metabotropic KAR signaling in Netol knock-out mice; however, $200 \mathrm{~nm}$ is 10 -fold above the dose required to deliver the maximum response for this KAR function (Ruiz et al., 2005). Overall, the loss of $\mathrm{sEPSC}_{\mathrm{KA}} \mathrm{s}$ and ionotropic/metabotropic responses to $200 \mathrm{~nm}$ kainate in the absence of Netol indicate that very few receptors containing either high-affinity subunits $(\sim 5 \mathrm{~nm}$ kainate; GluK4,5) or low-affinity subunits ( $\sim 50 \mathrm{~nm}$ kainate; GluK1-3) remain functional in the membrane. Importantly, the loss of Neto proteins does not reduce the total abundance of KAR subunits available to CA3 pyramidal cells (Straub et al., 2011, Tang et al., 2011), indicating that the current findings reflect a specific deficit in synaptic (and perhaps overall membrane) KAR localization.

Like Neto1, GluK2 and GluK5 are particularly abundant at the MF-CA3 synapse (Darstein et al., 2003; Ruiz et al., 2005; Straub et al., 2011) where they are functionally intertwined. GluK2/3 immunoreactivity likely reflects GluK2 expression as the labeling is extremely limited in GluK2 knock-out mice and all but absent in stratum lucidum (Fig. 1H; Darstein et al., 2003; Straub et al., 2011). In the mossy fiber pathway, GluK2 and GluK5 coassemble and Neto 1 coimmunoprecipitates with both (Straub et al., 2011; Tang et al., 2011). GluK5 cannot reach the plasma membrane alone (Ren et al., 2003), and GluK2/3 immunolabeling is drastically reduced in GluK4/ GluK5 knockouts at MF-CA3 synapses (Fernandes et al., 2009). Thus, both GluK2 and GluK5 are likely to be reduced at the PSD in Neto-null mice (substantiated by immunoblot, Tang et al., 2011; but see Straub et al., 2011), whether Neto1 targets GluK2, GluK5, or both to the synapse.

In contrast with reduced GluK2/3 labeling, postsynaptic GluN2B labeling was strikingly increased at MF-CA3 synapses in Neto-null mice. A corresponding decrease in GluN2A, similar to the reduction described in CA1 of Neto1 knock-out mice ( $\mathrm{Ng}$ et al., 2009; but see Straub et al., 2011), would have accounted for the unchanged EPSC $_{\text {NMDA }}$ amplitude. Although GluN2A and GluN2B subunit densities cannot be directly compared with each other due to potential differences in antibody efficacy, the relative changes between wild-type and knock-out mice did not demonstrate any decrease in GluN2A commensurate with the GluN2B increase in Neto-null mice. Therefore, increased GluN2B, together with unaltered NMDARmediated current, suggest that diheteromeric GluN1/GluN2A receptors in mature wild-type mice become triheteromeric GluN1/GluN2A/GluN2B receptors in Neto-null mice. Indeed, the predominant influence of GluN2A on deactivation in such triheteromeric receptors may account for why no difference in EPSC kinetics was found between wild-type and Netol knockout mice (Tovar et al., 2013).

Although preserved at the MF-CA3 synapse in Neto1 knockout mice, EPSC $_{\mathrm{NMDA}}$ amplitude was decreased at both SC-CA1 synapses and recurrent $\mathrm{CA} 3$ synapses in stratum radiatum (Ng et al., 2009; Tang et al., 2011). The difference between effects on NMDAR transmission at CA3 pyramidal versus granule cell terminals may derive from stronger Neto expression in stratum lucidum over stratum radiatum. Although Neto 2 contributions cannot be ruled out, other studies have linked Netol to changes in NMDARs (Ng et al., 2009; Tang et al., 2011; Cousins et al., 2013), and in this study ifenprodil sensitivity was enhanced in Neto1 knockouts, implicating Neto1 in the regulation of MFCA3 synapse NMDAR subunit composition.

Neto1 regulation of NMDAR subunit composition at MFCA3 synapses potentially influences downstream intracellular signaling. In addition, the targeting function of Neto1, combined with its established role in regulating KAR channel properties, have the capacity to greatly influence KAR availability and synaptic participation. Both ionotropic and metabotropic KAR signaling were disrupted in Netol knockouts, substantiating the influence of auxiliary proteins over these receptors that are important for MF-CA3 transmission and plasticity, and likely cooperating to restrict excitability in mice lacking Neto1.

\section{References}

Berg LK, Larsson M, Morland C, Gundersen V (2013) Pre-and postsynaptic localization of NMDA receptor subunits at hippocampal mossy fibre synapses. Neuroscience 230:139-150. CrossRef Medline

Copits BA, Swanson GT (2012) Dancing partners at the synapse: auxiliary subunits that shape kainate receptor function. Nat Rev Neurosci 13:675686. CrossRef Medline

Copits BA, Robbins JS, Frausto S, Swanson GT (2011) Synaptic targeting and functional modulation of GluK1 kainate receptors by the auxiliary neuropilin and tolloid-like (NETO) proteins. J Neurosci 31:7334-7340. CrossRef Medline

Cousins SL, Innocent N, Stephenson FA (2013) Netol associates with the NMDA receptor/amyloid precursor protein complex. J Neurochem 126: 554-564. CrossRef Medline

Darstein M, Petralia RS, Swanson GT, Wenthold RJ, Heinemann SF (2003) Distribution of kainate receptor subunits at hippocampal mossy fiber synapses. J Neurosci 23:8013-8019. Medline

Fernandes HB, Catches JS, Petralia RS, Copits BA, Xu J, Russell TA, Swanson GT, Contractor A (2009) High-affinity kainate receptor subunits are necessary for ionotropic but not metabotropic signaling. Neuron 63:818 829. CrossRef Medline

Fisahn A, Heinemann SF, McBain CJ (2005) The kainate receptor subunit GluR6 mediates metabotropic regulation of the slow and medium AHP currents in mouse hippocampal neurones. J Physiol 562:199-203. CrossRef Medline

Fisher JL, Mott DD (2013) Modulation of homomeric and heteromeric kainate receptors by the auxiliary subunit Netol. J Physiol 591:4711-4724. CrossRef Medline

Fritschy JM, Weinmann O, Wenzel A, Benke D (1998) Synapse-specific localization of NMDA and GABA(A) receptor subunits revealed by antigen-retrieval immunohistochemistry. J Comp Neurol 390:194-210. CrossRef Medline

Melyan Z, Wheal HV, Lancaster B (2002) Metabotropic-mediated kainate receptor regulation of IsAHP and excitability in pyramidal cells. Neuron 34:107-114. CrossRef Medline

Ng D, Pitcher GM, Szilard RK, Sertié A, Kanisek M, Clapcote SJ, Lipina T, Kalia LV, Joo D, McKerlie C, Cortez M, Roder JC, Salter MW, McInnes RR (2009) Neto1 is a novel CUB-domain NMDA receptor-interacting protein required for synaptic plasticity and learning. PLoS Biol 7:e41. CrossRef Medline

Petralia RS, Wenthold RJ (1999) Immunocytochemistry of NMDA receptors. Methods Mol Biol 128:73-92. CrossRef Medline

Petralia RS, Sans N, Wang YX, Wenthold RJ (2005) Ontogeny of postsynaptic density proteins at glutamatergic synapses. Mol Cell Neurosci 29: 436-452. CrossRef Medline

Ren Z, Riley NJ, Garcia EP, Sanders JM, Swanson GT, Marshall J (2003) Multiple trafficking signals regulate kainate receptor KA2 subunit surface expression. J Neurosci 23:6608-6616. Medline

Ruiz A, Sachidhanandam S, Utvik JK, Coussen F, Mulle C (2005) Distinct subunits in heteromeric kainate receptors mediate ionotropic and metabotropic function at hippocampal mossy fiber synapses. J Neurosci 25:11710-11718. CrossRef Medline

Straub C, Hunt DL, Yamasaki M, Kim KS, Watanabe M, Castillo PE, Tomita S (2011) Distinct functions of kainate receptors in the brain are deter- 
mined by the auxiliary subunit Netol. Nat Neurosci 14:866-873. CrossRef Medline

Tang M, Pelkey KA, Ng D, Ivakine E, McBain CJ, Salter MW, McInnes RR (2011) Neto1 is an auxiliary subunit of native synaptic kainate receptors. J Neurosci 31:10009-10018. CrossRef Medline

Tang M, Ivakine E, Mahadevan V, Salter MW, McInnes RR (2012) Neto2 interacts with the scaffolding protein GRIP and regulates synaptic abundance of kainate receptors. PLoS One 7:e51433. CrossRef Medline

Tomita S, Castillo PE (2012) Neto1 and Neto2: auxiliary subunits that determine key properties of native kainate receptors. J Physiol 590:22172223. CrossRef Medline

Tovar KR, McGinley MJ, Westbrook GL (2013) Triheteromeric NMDA re- ceptors at hippocampal synapses. J Neurosci 33:9150-9160. CrossRef Medline

Watanabe M, Fukaya M, Sakimura K, Manabe T, Mishina M, Inoue Y (1998) Selective scarcity of NMDA receptor channel subunits in the stratum lucidum (mossy fibre-recipient layer) of the mouse hippocampal CA3 subfield. Eur J Neurosci 10:478-487. CrossRef Medline

Yan D, Tomita S (2012) Defined criteria for auxiliary subunits of glutamate receptors. J Physiol 590:21-31. CrossRef Medline

Zhang W, St-Gelais F, Grabner CP, Trinidad JC, Sumioka A, MorimotoTomita M, Kim KS, Straub C, Burlingame AL, Howe JR, Tomita S (2009) A transmembrane accessory subunit that modulates kainate-type glutamate receptors. Neuron 61:385-396. CrossRef Medline 